\title{
Energy balance in critical illness
}

\author{
Lindsay D. Plank* and Graham L. Hill \\ Department of Surgery, University of Auckland, Auckland, New Zealand
}

\begin{abstract}
Energy balance is the difference between energy consumed and total energy expended. Over a given period of time it expresses how much the body stores of fat, carbohydrate and protein will change. For the critically-ill patient, who characteristically exhibits raised energy expenditure and proteolysis of skeletal muscle, energy balance information is valuable because underfeeding or overfeeding may compromise recovery. However, there are formidable difficulties in measuring energy balance in these patients. While energy intake can be accurately recorded in the intensive care setting, the measurement of total energy expenditure is problematic. Widely used approaches, such as direct calorimetry or doubly-labelled water, are not applicable to the critically ill patient. Energy balance was determined over periods of 5-10 d in patients in intensive care by measuring changes in the fat, protein and carbohydrate stores of the body. Changes in total body fat were positively correlated with energy balance over the $5 \mathrm{~d}$ study periods in patients with severe sepsis ( $n$ 24, $r 0 \cdot 56, P=0 \cdot 004)$ or major trauma $(n 24, r 0 \cdot 70, P<0 \cdot 0001)$. Fat oxidation occurred in patients whose energy intake was insufficient to achieve energy balance. Changes in body protein were independent of energy balance. These results are consistent with those of other researchers who have estimated total energy requirements from measurements of $\mathrm{O}_{2}$ consumption and $\mathrm{CO}_{2}$ production. In critically-ill patients achievement of positive non-protein energy balance or total energy balance does not prevent negative $\mathrm{N}$ balance. Nutritional therapy for these patients may in the future focus on glycaemic control with insulin and specialised supplements rather than on energy balance per se.
\end{abstract}

Critical illness: Energy balance: Nutritional support

Energy balance is the difference between energy consumed and total energy expended. For critically-ill patients in the intensive care unit (ICU) there are formidable technical difficulties in measuring energy balance. While energy intakes can be accurately recorded in this setting the measurement of total energy expenditure (TEE) is problematic. Energy balance over a given period of time expresses how much the body stores of fat, carbohydrate and protein will change. Energy balance was determined over the first 2 weeks of intensive care in critically-ill patients by measuring changes in the fat, protein and carbohydrate stores of the body. These measurements were possible because of advances in body composition technology and the close proximity to the ICU of our facility, which is purposely designed to carry out measurements in the critically-ill patient.

\section{Measurement of energy balance from changes in body composition \\ Patients and methods}

The changes in total body fat (TBF), total body protein (TBP) and total body glycogen (TBG) over two consecutive $5 \mathrm{~d}$ periods $(\triangle \mathrm{TBF}, \triangle \mathrm{TBP}$ and $\triangle \mathrm{TBG}$ respectively) were measured in twelve patients with severe sepsis and twelve patients with major trauma as soon as these patients became haemodynamically stable (Uehara et al. 1999). Clinical details are given in Table 1 . Of the patients with sepsis one died on day 28 after admission to the ICU and the remaining eleven survived and left hospital in a median time of $35 \mathrm{~d}$. All the patients with trauma survived to leave hospital in a median $31 \mathrm{~d}$. Ten of the twelve patients with trauma sustained a major blunt head injury, the other two suffered

\footnotetext{
Abbreviations: ICU, intensive care unit; TBF, total body fat; TBG, total body glycogen; TBP, total body protein; TEE, total energy expenditure; $\Delta \mathrm{TBF}, \Delta \mathrm{T}$ $\mathrm{BG}, \triangle \mathrm{TBP}$, changes in TBF, TBG and TBP respectively over $5 \mathrm{~d}$ periods.

*Corresponding author: Dr Lindsay D. Plank, fax +649377 9656, email 1.plank@auckland.ac.nz
} 
Table 1. Demographic and clinical data of twelve patients with serious sepsis and twelve patients with critical injury for whom energy balance was determined (Values are medians and ranges)

\begin{tabular}{|c|c|c|c|c|}
\hline \multirow[b]{2}{*}{ Patient group. . . . } & \multicolumn{2}{|c|}{ Sepsis } & \multicolumn{2}{|c|}{ Trauma } \\
\hline & Median & Range & Median & Range \\
\hline \multicolumn{5}{|l|}{ No. of patients } \\
\hline Male & 8 & & 9 & \\
\hline Female & 4 & & 3 & \\
\hline Age (years) & 67 & $25-84$ & 34 & $18-54$ \\
\hline ISS & & & 33.5 & $26-50$ \\
\hline APACHE II & 23 & $15-34$ & & \\
\hline Period on ventilator (d) & 13 & $7-28$ & 7 & $1-20$ \\
\hline ICU stay (d) & 15 & $7-29$ & 11.5 & $3-24$ \\
\hline Hospital stay (d) & 34.5 & $25-120$ & 31 & $22-58$ \\
\hline
\end{tabular}

ISS, injury severity score; APACHE II, acute physiology and chronic health evaluation score; ICU, intensive care unit.

blunt abdominal trauma. The median time from admission to the ICU to the first body composition measurement was $3 \mathrm{~d}$ in both the sepsis (range 1-8d) and the trauma (range $1-4 \mathrm{~d}$ ) groups.

TBF and bone mineral content were measured by dualenergy X-ray absorptiometry, TBP by in vivo neutron activation analysis and total body water by ${ }^{3} \mathrm{H}_{2} \mathrm{O}$ dilution. Total body mineral was obtained as the sum of bone mineral content and an estimated non-bone mineral content, while TBG was derived according to the following equation (Franch-Arcas et al. 1994):

$$
\mathrm{TBG}=\mathrm{BW}-(\mathrm{TBF}+\mathrm{TBW}+\mathrm{TBP}+\mathrm{TBM}),
$$

where BW is body weight, TBW is total body water and TBM is total body mineral.

Patients with sepsis were provided with enteral or intravenous nutrition as clinically determined. The energy distribution of the enteral feed (Osmolite; Ross Laboratories, Columbus, OH, USA) was (\%): 15 protein, 32 fat, 53 carbohydrate, and of the intravenous feed was typically (\%): 20 protein (Synthamin-17; Baxter, Sydney, Australia), 40 fat (Intralipid; Baxter), 40 carbohydrate. The nutritional support aim was to provide $146 \mathrm{~kJ}$ (35 kcal)/kg body weight per $\mathrm{d}$ for these patients. As soon as clinically indicated, patients with trauma were given enteral feeding with an elemental formula (AlitraQ; Ross Laboratories) with an energy distribution of (\%): 23 protein, 14 fat, 63 carbohydrate. The aim was to provide energy at a level between 125 and $150 \%$ measured resting energy expenditure. Ten of the twelve patients with sepsis received intravenous nutrition while the others were fed enterally. Feeding began in these patients at a median $4 \cdot 5$ (range 1-11) d after admission to the ICU. Enteral feeding began in the patients with trauma at a median 2 (range 0-4) d after admission. Energy intake before intravenous or enteral feeding was provided by glucose and albumin infusions. Energy balance was determined as:

$$
\mathrm{EB}(\mathrm{kJ} / \mathrm{d})=39.5 \Delta \mathrm{TBF}+19.68 \Delta \mathrm{TBP}+17.49 \Delta \mathrm{TBG},
$$

where EB is energy balance and $\triangle \mathrm{TBF}, \triangle \mathrm{TBP}$ and $\triangle \mathrm{TBG}$ are expressed in $\mathrm{g} / \mathrm{d}$ and the multiplication factors represent
Table 2. Energy intake (EI) relative to body weight (BW) and measured resting energy expenditure (REE) calculated from consecutive $5 \mathrm{~d}$ study periods in twelve patients with sepsis and twelve patients with trauma*

(Mean values with their standard errors)

\begin{tabular}{lcclcc}
\hline & \multicolumn{2}{c}{ El/BWt (kJ/kg per d) } & & \multicolumn{2}{c}{ El/REE } \\
\cline { 2 - 3 } \cline { 5 - 6 } & Mean & SE & & Mean & SE \\
\hline Patients with sepsis & & & & & \\
$\quad$ First 5 d period & 103 & 10 & & 0.98 & 0.09 \\
$\quad$ Second 5 d period & 120 & 12 & & 1.04 & 10 \\
$P \dagger$ & 0.10 & & & 0.48 & \\
Patients with trauma & & & & & \\
$\quad$ First 5 d period & 84 & 7 & & 0.70 & 0.05 \\
$\quad$ Second 5 d period & 121 & 10 & & 0.87 & 0.05 \\
$P \dagger$ & 0.0007 & & & 0.039 & \\
\hline
\end{tabular}

* $\mathrm{BW}$ and REE were averaged over the $5 \mathrm{~d}$ period; for details of patients and procedures, see Table 1 and p. 546.

†Comparison of first and second periods by paired $t$ test.

the energy equivalent of the oxidation per $g$ for each of these fuels (Livesey \& Elia, 1988).

\section{Results and discussion}

Total energy intakes for the patients with sepsis were 7753 $(\mathrm{SE} 732) \mathrm{kJ} / \mathrm{d}$ and $8540(\mathrm{SE} 795) \mathrm{kJ} / \mathrm{d}(P=0 \cdot 27)$ during the first and second $5 \mathrm{~d}$ periods respectively. Energy intake for the patients with trauma was significantly higher during the second $(8259(\mathrm{SE} 448) \mathrm{kJ} / \mathrm{d})$ than during the first $5 \mathrm{~d}$ period (6163 (SE 481) kJ/d; $P=0 \cdot 002)$.

$\Delta \mathrm{TBF}, \Delta \mathrm{TBP}$ and $\Delta \mathrm{TBG}(\mathrm{kJ} / \mathrm{d})$, and the resultant energy balance over the two consecutive $5 \mathrm{~d}$ periods are shown in Fig. 1 for the sepsis and trauma groups. Over the first $5 \mathrm{~d}$ period little change in the protein, fat and glycogen stores was seen in the patients with sepsis and energy balance was approximately zero. In contrast, the patients with trauma were in negative energy balance $(P=0 \cdot 05)$ over this period with a significant loss of body protein $(P=0.004)$, despite the fact that feeding started earlier in the trauma group. This finding probably reflects the fact that higher energy intakes were possible with intravenous nutrition in the patients with sepsis and that all the patients with sepsis were ventilated over the first $5 \mathrm{~d}$ period, while in the trauma group two patients were taken off ventilation before this period and three patients came off ventilation during this period. Over the second $5 \mathrm{~d}$ period, during which the hypermetabolic response was maximal, both groups of patients lost significant body protein and were in marked negative energy balance $(P<0.05$ in both cases; Fig. 1$)$. The patients with trauma lost significant body fat $(P=0.004)$ over this period.

In Table 2 the total energy intakes for the sepsis and trauma groups are expressed in terms of measured body weight and measured resting energy expenditure over the $5 \mathrm{~d}$ periods of study. It can be seen that for neither group were the targets of nutritional support realised. However, for the patients with sepsis the intake was in accord with American Society for Parenteral and Enteral Nutrition guidelines (American Society for Parenteral and Enteral Nutrition Board of Directors, 1995), i.e. 105-125 kJ (25-30 kcal)/kg per $\mathrm{d}$ or measured resting energy expenditure. Intake in the 
(a)

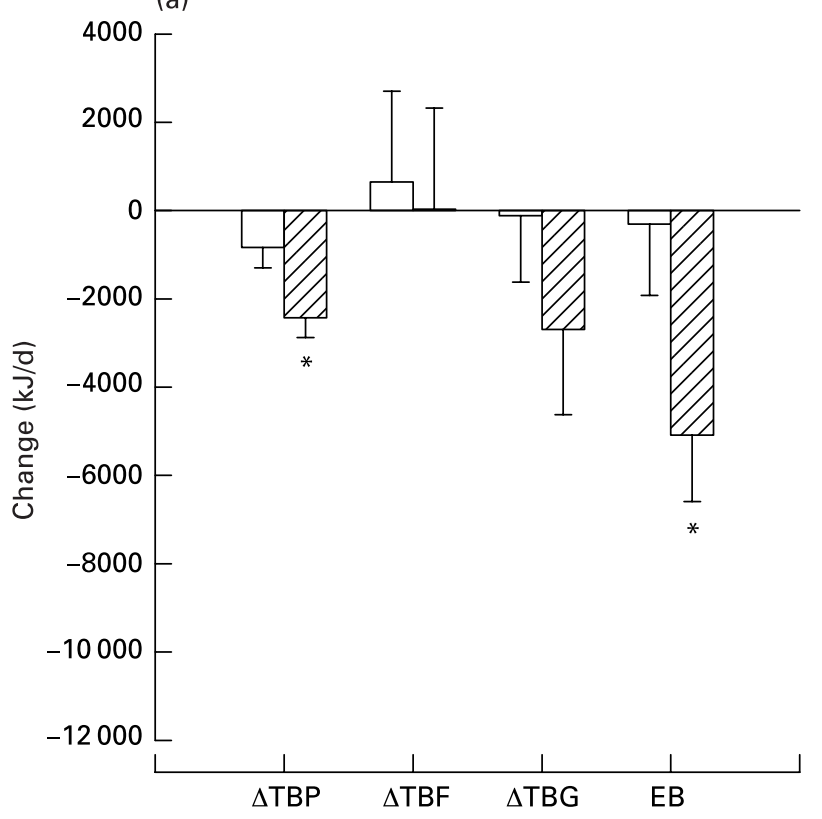

(b)

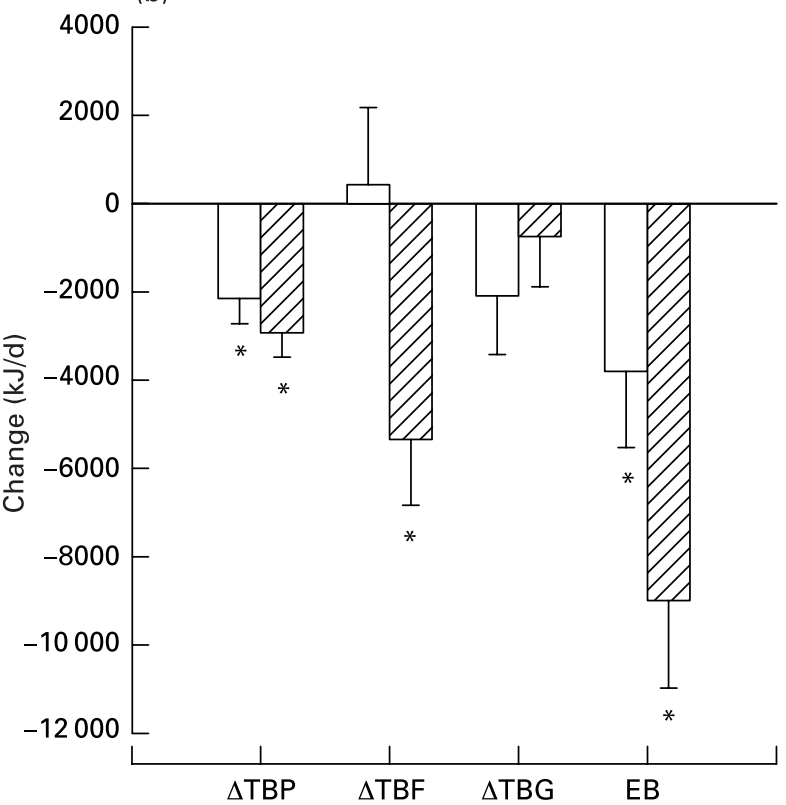

Fig. 1. Changes $(\mathrm{kJ} / \mathrm{d})$ in total body protein $(\Delta \mathrm{TBP})$, total body fat $(\Delta \mathrm{TBF})$ and total body glycogen $(\Delta \mathrm{TBG})$ and resultant energy balance (EB) over consecutive $5 \mathrm{~d}$ periods ( $\square$, first $5 \mathrm{~d}$; $\mathbb{m}$, second $5 \mathrm{~d}$ ) for (a) twelve patients with sepsis and (b) twelve patients with trauma soon after admission to the intensive care unit. For details of patients and procedures, see Table 1 and p. 546 . Values are means with their standard errors represented by vertical bars. Mean values were significantly different from zero: ${ }^{*} P<0.05$.

(a)

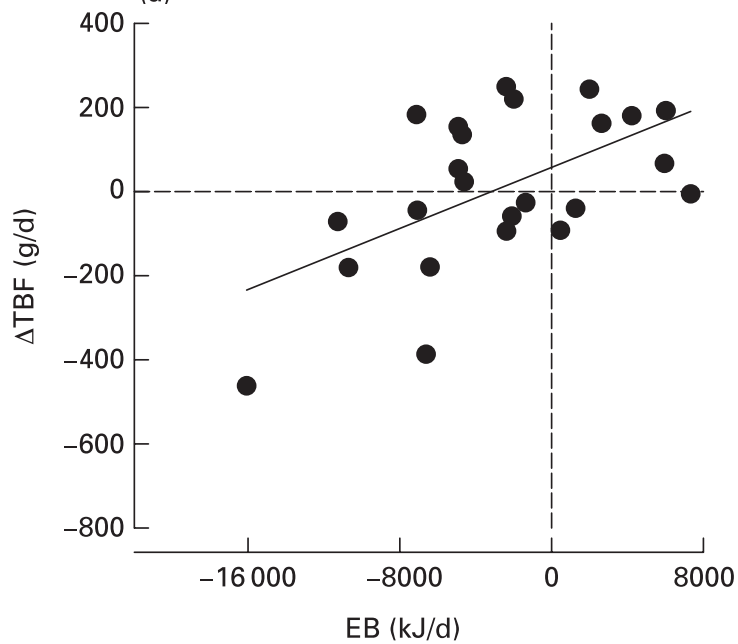

(b)

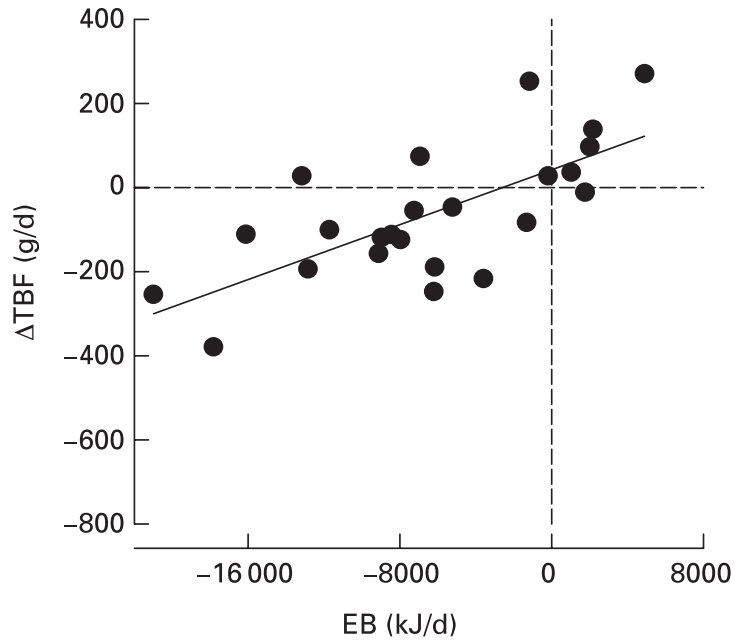

Fig. 2. Relationship between changes in total body fat $(\triangle T B F)$ and energy balance (EB) over $5 \mathrm{~d}$ periods for (a) twelve patients with sepsis and (b) twelve patients with trauma. Regression equations are: $\triangle T B F=0.076 \mathrm{~EB}+57$, SE of estimate $158 \mathrm{~g} / \mathrm{d}, r 0.56, P=0.004$ for patients with sepsis and $\Delta \mathrm{TBF}=0.068 \mathrm{~EB}+42$, SE of estimate $115 \mathrm{~g} / \mathrm{d}, r 0.70, P<0.0001$ for patients with trauma. For details of subjects and procedures, see Table 1 and p. 546.

trauma group fell short of meeting these recommendations over the first $5 \mathrm{~d}$. During the second $5 \mathrm{~d}$ period, while intake reached $121 \mathrm{~kJ}(29 \mathrm{kcal}) / \mathrm{kg}$ per $\mathrm{d}$ the patients remained in negative energy balance.

Fig. 2 shows the individual changes in TBF as a function of energy balance. For both sepsis and trauma groups there is a positive correlation between $\triangle \mathrm{TBF}$ and energy balance ( $P=0.004$ and $P<0.0001$ respectively), so that fat oxidation occurred when energy intake fell short of energy requirements and fat was synthesised when energy intake exceeded metabolic requirements. Neither $\triangle \mathrm{TBP}$ nor $\triangle \mathrm{TBG}$ were correlated with energy balance over the study periods. The regression for $\triangle \mathrm{TBF} v$. energy balance was not significantly different between the two groups $(P=0.78$ for slopes; $P=0.86$ for elevations; covariance analysis). The regression equation for the combined data was: 
Table 3. Changes in energy stores over a $5 \mathrm{~d}$ period in patients with sepsis or trauma whose energy balance (EB) was positive or negative* (Mean values with their standard errors)

\begin{tabular}{|c|c|c|c|c|c|}
\hline & \multicolumn{2}{|c|}{$\mathrm{EB}>0(n 13)$} & \multicolumn{2}{|c|}{$\mathrm{EB}<0(n 35)$} & \multirow{2}{*}{$\begin{array}{c}\text { Statistical significance of difference } \\
\text { between groups } \uparrow: P\end{array}$} \\
\hline & Mean & SE & Mean & SE & \\
\hline$\Delta \operatorname{TBF}(\mathrm{g} / \mathrm{d})$ & 95 & 32 & -72 & 29 & 0.0025 \\
\hline Statistical significance of change: $P=$ & \multicolumn{2}{|c|}{$0.012 \ddagger$} & \multicolumn{2}{|c|}{0.018} & \\
\hline$\Delta \operatorname{TBP}(\mathrm{g} / \mathrm{d})$ & -70 & 31 & -119 & 15 & 0.12 \\
\hline Statistical significance of change: $P=$ & \multicolumn{2}{|c|}{0.044} & \multicolumn{2}{|c|}{$<0.0001$} & \\
\hline$\Delta \mathrm{TBG}(\mathrm{g} / \mathrm{d})$ & 49 & 57 & -129 & 52 & 0.062 \\
\hline Statistical significance of change: $P=$ & \multicolumn{2}{|c|}{0.41} & \multicolumn{2}{|c|}{0.018} & \\
\hline
\end{tabular}

$\triangle T B F, \triangle T B P, \triangle T B G$, changes in total body fat, total body and total body glycogen respectively.

${ }^{*}$ For details of subjects and procedures, see Table 1 and p. 546.

†Unpaired $t$ test.

$\ddagger$ Two-tailed $t$ test.

\footnotetext{
$\Delta \mathrm{TBF}(\mathrm{g} / \mathrm{d})=0.072 \mathrm{~EB}+52(\mathrm{SEE} 135 \mathrm{~g} / \mathrm{d}, r 0.64$, $P<0.001)$,
}

where EB is energy balance and SEE is SE of estimate

This relationship between changes in TBF and energy balance is explored further in Table 3, where it can be seen that for thirteen of the study periods energy intake exceeded TEE. In this subgroup there was a significant gain in fat over the $5 \mathrm{~d}$ period $(P=0.012)$. A significant loss of fat occurred for the remaining thirty-five study periods $(P=0.018)$, for which there was also a significant loss of glycogen $(P=0.018)$. Significant and similar losses of protein were recorded for both subgroups.

The present results, based on a number of published studies carried out in our facility (Franch-Arcas et al. 1994; Monk et al. 1996; Plank et al. 1998) in which integrated $\triangle \mathrm{TBF}$ have been measured over the first or second week after the onset of critical illness, confirm that fat is not an obligatory energy source in critically-ill patients. An earlier study of patients with sepsis from our laboratory (Streat et al. 1987) suggested, on the basis of a less direct measurement of TBF, that aggressive nutritional support could prevent lipolysis. $\triangle \mathrm{TBF}$ and $\triangle \mathrm{TBG}$ could not be separated in that study, although the conclusions support the present results.

\section{Alternative methods of measuring energy balance in critically-ill patients}

Continuous whole-body calorimetry, in which all energy intake is measured, provides the most accurate means of assessing energy balance (Jebb et al. 1996; Jebb \& Prentice, 1997). For obvious reasons this technique is not applicable to hospital patients.

The doubly-labelled-water technique for measuring total free-living energy expenditure, typically averaged over periods of $10-14 \mathrm{~d}$, has been widely applied in healthy individuals (Coward, 1988). Several assumptions underlie the doubly-labelled-water technique, including steady-state $\mathrm{CO}_{2}$ and $\mathrm{H}_{2} \mathrm{O}$ turnover and constant body water pool size during the measurement period (Speakman, 1990). These assumptions are seriously violated in critically-ill patients during the first or second week after their admission. Massive shifts in body water may occur during this period, together with large changes in $\mathrm{CO}_{2}$ production (Monk et al. 1996; Plank et al. 1998). Critically-ill patients with sepsis, studied by the doubly-labelled-water method (Koea et al. 1995), were out of the ICU when measured and in a relatively steady state in which body weight did not deviate by $>5 \%$ over the $10 \mathrm{~d}$ study period.

In principle, continuous indirect calorimetry can be used to measure TEE in critically-ill patients. This technique measures $\mathrm{O}_{2}$ consumption and $\mathrm{CO}_{2}$ production rates, from which energy expenditure can be calculated knowing the urinary $\mathrm{N}$ excretion rate (Livesey \& Elia, 1988). In practice little error is introduced into the calculation of energy metabolism if an assumed $\mathrm{N}$ excretion rate is used (Bursztein et al. 1989). While it has the advantage of providing estimates of TEE over periods of $\leq 1 \mathrm{~d}$, the indirect calorimetry approach poses formidable technical difficulties for patients early in the course of their illness. It is suitable for patients on mechanical ventilation, but the errors in $\mathrm{O}_{2}$ consumption measurement increase markedly with the percentage of $\mathrm{O}_{2}$ in the air inspired, particularly $>60 \%$ (Chioléro et al. 1993). Recent commercial developments have improved performance in the range $60-80 \% \mathrm{O}_{2}$ inspired. Conditions such as changing metabolic acid-base status and the use of extra-corporeal $\mathrm{CO}_{2}$ removal or oxygenation devices effectively rule out the indirect calorimetry method (Chioléro et al. 1993; Brandi et al. 1997). These situations commonly apply in the intensive care setting. Frankenfield et al. (1994) carried out $24 \mathrm{~h}$ indirect calorimetry measurements to determine TEE in patients with sepsis or trauma, who were intubated and heavily sedated. Similarly, in small studies of mechanicallyventilated patients Smyrnios et al. (1997) and Weissman et al. (1986) measured $24 \mathrm{~h}$ energy expenditure. These patients were neither comatose nor receiving neuromuscular blocking agents. All these studies were designed to investigate relationships between measures of resting energy expenditure and TEE and the optimal timing and duration of resting indirect calorimetry measurements to best estimate TEE. These authors did not report energy intake data so that energy balance in their patients cannot be examined. 


\section{Control of energy balance in critical illness}

\section{Metabolic response to severe injury and infection}

It was 60 years ago that Cuthbertson (1942) introduced the concept of 'ebb' and 'flow' phases in describing the metabolic response to traumatic injury. The ebb phase, lasting perhaps $24-48 \mathrm{~h}$, characterised by general fuel mobilisation and hypometabolism, is followed by the flow phase, characterised by elevated energy expenditure (hypermetabolism) and breakdown of body tissues (catabolism). Our studies of critically-injured patients (Monk et al. 1996) showed that this hypermetabolism peaked at about $10 \mathrm{~d}$ post injury. Profound metabolic interchanges occur during this phase and the increased $\mathrm{O}_{2}$ consumption serves to support these inter-organ substrate exchanges. The metabolic picture seen in major traumatic injury is a generalised response that is similar to that seen following serious sepsis (Plank \& Hill, 2000) and major burns (Wolfe, 1996).

Finely-regulated metabolic adaptations allow healthy individuals to sustain prolonged periods without food. When starvation extends beyond 2-3 d, these adaptations include a stimulation of ketogenesis and ketone body oxidation with suppression of protein breakdown and gluconeogenesis. In contrast, in critically-ill patients these adaptations do not occur and accelerated protein-energy malnutrition ensues, with increased risk of infection and compromised recovery unless nutritional support is instituted.

Reprioritisation of the normal nutritional homeostasis of the body occurs in response to the hypermetabolism and catabolism of the systemic metabolic response. Hyperglycaemia, hypertriacylglycerolaemia, high lactate levels and high non-esterified fatty acid concentrations are characteristic of the critically-ill patient and indicate major derangements in carbohydrate, fat and protein metabolism. Optimal nutritional management of these patients requires an understanding of fuel utilisation and the control of energy balance in the flow phase of critical illness.

\section{Intermediary metabolism}

The neuroendocrine response to critical illness is associated with elevated blood concentrations of glucagon, catecholamines and cortisol, hormones that stimulate endogenous glucose production by promoting gluconeogenesis and glycogenolysis. These hormonal changes are mediated by a complex array of neutrophil and macrophage products (Hill, 2000). This hormonal and inflammatory mediator milieu strongly influences priorities for substrate utilisation in critical illness. Hyperglycaemia associated with insulin resistance (Shangraw et al. 1989; McCowen et al. 2001) is one of the most prominent clinical manifestations of the changes in substrate metabolism brought about by critical illness, and probably occurs as a result of the accelerated gluconeogenesis. Compared with healthy subjects, glucose or insulin infusions are markedly less effective in suppressing gluconeogenesis (Long et al. 1976).

Regardless of aetiology, enhanced lipolytic activity is characteristic of the metabolic response to severe stress. Fatty acids are generally released from adipose tissue in amounts exceeding energy requirements and those not oxidised as fuel are re-esterified to triacylglycerol (Klein et al. 1991). Hypertriacylglycerolaemia and hepatic steatosis commonly occur (Wolfe \& Martini, 2000). In fasted patients fatty acids predominate as the energy substrate since the energy substrate requirements are not satisfied by hepatic glucose production. In fed stressed patients fat continues to be an important contributor to energy production (Klein et al. 1991), in contrast to healthy individuals in whom lipolysis is suppressed by provision of normal amounts of glucose.

Accelerated catabolism of muscle protein is universal in critically-ill patients. The mobilisation of amino acids from muscle provides substrate for gluconeogenesis and for increased hepatic synthesis to support immune defence and wound healing. Isotopic tracer methodology has demonstrated that net whole-body protein catabolism is reduced, but not eliminated, by intravenous nutrition (Shaw et al. 1987). In that study patients with sepsis established on intravenous nutrition for an average of $8 \mathrm{~d}$ with non-protein energy as $50 \%$ fat and $50 \%$ glucose achieved optimal protein sparing at protein intakes of $1.5 \mathrm{~g} / \mathrm{kg}$ per $\mathrm{d}$. Net protein catabolism was greater at both lower $(1 \cdot 1 \mathrm{~g} / \mathrm{kg}$ per d) and higher $(2.2 \mathrm{~g} / \mathrm{kg}$ per $\mathrm{d})$ protein intakes. Results that are in broad agreement with these values were obtained in a study of critically-ill patients who had $\triangle T$ TBP measured over $10 \mathrm{~d}$ soon after admission to intensive care (Ishibashi et al. 1998).

The profound disturbances of intermediary metabolism in critically-ill patients necessitate detailed investigation of the timing, macronutrient balance and energy provision of nutritional support for these patients. The route of such support is also an issue that has received considerable attention, but full consideration of this issue is beyond the scope of the present article.

\section{Nutritional support of the critically-ill patient}

The hypermetabolic state and accelerated proteolysis of skeletal muscle in critically-ill patients, particularly if combined with pre-existing malnutrition, leads to marked immunosuppression, muscle weakness and increased risk of nosocomial infection. Artificial nutritional support is unquestionably indicated in these patients. However, is it necessary or desirable to achieve positive energy balance, at least in the early flow phase of illness? Evidence that nutritional support actually influences clinically-important outcomes is difficult to obtain (Heyland, 1998). It cannot be assumed that providing energy intake to match energy expenditure is optimal for the management of critically-ill patients (Zaloga \& Roberts, 1994).

As shown earlier, it is clear that nutritional support can ameliorate the $\mathrm{N}$ losses that occur with critical illness. In the study by Streat et al. (1987) eight severely-septic patients received $11300 \mathrm{~kJ}(2700 \mathrm{kcal})$ non-protein energy and $14230 \mathrm{~kJ}(3400 \mathrm{kcal})$ total energy/d over the $10 \mathrm{~d}$ of study, which was equivalent to $142 \mathrm{~kJ}(34 \mathrm{kcal})$ non-protein energy or $180 \mathrm{~kJ}$ (43 kcal) total energy/kg per $\mathrm{d}$, and these patients were in positive energy balance. Five of these patients came off mechanical ventilation during the study period. While marked body fat gain was measured, $12.5 \%$ of the body protein was lost over the $10 \mathrm{~d}$ of study. Indeed, TBP losses sustained by these patients over the $10 \mathrm{~d}(1.5(\mathrm{SE} 0 \cdot 3) \mathrm{kg})$ 
were slightly greater than those of the twelve patients with sepsis discussed earlier (0.9 (SE 0.2) kg; $P=0.04)$, who were in negative energy balance. In critically-ill patients with multiple injuries Frankenfield et al. (1997) found that achievement of energy balance (non-protein energy or total energy), compared with moderate energy deficit, led to fat deposition but did not improve $\mathrm{N}$ balance. $\mathrm{N}$ loss did not correlate with energy balance. In these mechanicallyventilated patients energy intake was matched to resting energy expenditure to achieve energy balance. The authors concluded that high-protein hypoenergetic nutritional support is likely to be preferable for these patients. The question of hypoenergetic or hyperenergetic nutritional support for critically-ill patients continues to receive much attention.

\section{Underfeeding}

Underfeeding may lead to progressive malnutrition, with consequences that include increased complication rates, longer ICU stay and delayed convalescence. In general, studies that have documented inadequate energy intake by critically-ill patients have utilised enteral routes of administration. Factors that impede enteral feeding in such patients have been the subject of an editorial (Kirkland, 1999). McClave et al. (1999), in a study that examined delivery of enteral feeding to ICU patients, observed that only $66 \%$ of the target energy requirements were prescribed and only $78 \%$ on average of the volume prescribed was actually delivered, a result similar to that found in an earlier study (Adam \& Batson, 1997). Target feeding rates were set at $105-125 \mathrm{~kJ}(25-30 \mathrm{kcal}) / \mathrm{kg}$ per d. During the peak hypermetabolic phase of their illness this target rate would be insufficient to meet energy requirements in the patients in this study, further compounding the energy deficit (Uehara et al. 1999). Other recent studies have also documented cumulative energy deficits in enterally-fed ICU patients (Ebener et al. 2001) and have reported associations between energy deficit and length of ICU stay (Reid \& Campbell, 2001) or complication rates (Bollman et al. 2001). Many of the difficulties associated with enteral delivery are avoidable, and greater emphasis may need to be placed on overcoming these factors. With enteral feeding, gastrointestinal intolerance is the primary mechanism for protecting the patient from substrate excess. Mechanically-ventilated patients receiving narcotic sedation and/or muscle relaxants will have reduced splanchnic circulation and, as a consequence, compromised gut motility, which will limit effectiveness of nutrition by this route. The question of whether enteral administration should be preferred to the parenteral route is still the subject of much debate (Jeejeebhoy, 2001). It is widely perceived, and Jeejeebhoy (2001) would argue, erroneously, that parenteral feeding of critically-ill patients leads to more complications than enteral feeding. However, parenteral feeding is often associated with overfeeding of these patients.

\section{Overfeeding}

Overfeeding exacerbates the hyperglycaemia that accompanies the catabolic stress response, causes excess $\mathrm{CO}_{2}$ production that potentially prolongs the need for mechanical ventilation, may result in hepatic steatosis and hypertriacylglycerolaemia, and with excessive protein intake may produce azotaemia and metabolic acidosis (Klein et al. 1998). Critically-ill patients fed parenterally are vulnerable to overfeeding because of fewer impediments to the delivery of substantial energy loads by this mode of administration compared with enteral delivery. The patient receiving parenteral nutrition has no protective mechanism for dealing with overfeeding and must assimilate substrate. Increased sepsis complication rates in patients with major trauma have been attributed to overfeeding by the parenteral route (Jeejeebhoy, 2001). Hypoenergetic support for nonmalnourished critically-ill patients has been suggested for reducing overfeeding-related complications (Patino et al. 1999). A randomised trial (McCowen et al. 2000) comparing fat-free hypoenergetic parenteral nutrition with a standard parenteral nutrition regimen showed that deliberate underfeeding was not associated with reduced hyperglycaemia or infectious complications. $\mathrm{N}$ balance was markedly less negative in the standard group, who received $1.4 \mathrm{~g} / \mathrm{kg}$ per $\mathrm{d}$ protein, than in the hypoenergetic group, whose protein intake averaged $1.1 \mathrm{~g} / \mathrm{kg}$ per d. Analysis of glucose and fat metabolism in critical illness (Wolfe, 1997) suggests that no advantage is gained by providing fat in excess of essential requirements and that $100 \%$ glucose as a non-protein-energy source together with insulin may improve outcome for these patients compared with standard regimens with considerable energy provided as fat. Insulin, in addition to moderating the hyperglycaemic response, may offer additional advantages by stimulating protein anabolism. Van den Berghe et al. (2001) conducted a randomised trial, in mostly cardiac surgery patients, comparing intensive insulin therapy (maintenance of blood glucose between 4.4 and $6.1 \mathrm{mmol} / \mathrm{l}$ ) with conventional glucose control (maintenance of blood glucose between 10.0 and $11.1 \mathrm{mmol} / \mathrm{l})$. Intensive insulin therapy was associated with marked reductions in ICU and in-hospital mortality as well as morbidity. In that study patients were fed enterally or parenterally at a target rate of $84-126 \mathrm{~kJ}(20-30 \mathrm{kcal})$ non-protein energy $/ \mathrm{kg}$ per d with $20-40 \%$ non-protein energy as fat. Other work has shown that hyperglycaemia may have a marked effect on enhancing proteolysis (Flakoll et al.1993). It is reasonable to suggest that proteolysis in critically-ill patients receiving intensive insulin therapy for normalisation of blood glucose may be reduced both through the anabolic actions of insulin and through the reduction in hyperglycaemia. $\mathrm{N}$ balance measurements, however, were not reported for the study by Van den Berghe et al. (2001).

\section{Concluding remarks}

Understanding the metabolic response to serious infection and tissue injury and the effects on intermediary metabolism provides guidance for appropriate nutritional support of these patients. Research to date indicates that achievement of positive energy balance may not be appropriate for critically-ill patients over the crucial early flow phase. However, there is a lack of randomised trials directed at hyperenergetic $v$. hypoenergetic nutrition, which are not confounded by route of administration and other factors and 
which have acceptable clinical end points. For ethical reasons such trials may not be possible, and the extent to which under- or overfeeding can influence outcomes in critical illness remains unresolved.

Further investigations are needed in other groups of critically-ill patients of the potential benefits of glycaemic control with insulin therapy. Along with the clinical outcomes, examination of the impact of this therapy on protein catabolism in these patients will be of vital interest.

In order to optimise nutritional therapy for the criticallyill patient it may be more important to concentrate on specific micronutrients and specialised supplements rather than macronutrient and energy balance. Indeed, attention has focused over recent years beyond nutritional intervention as a primarily supportive measure in critically-ill patients to the use of specific nutrients, such as glutamine, arginine and $n-3$ fatty acids, which are designed to target specific deficiencies.

\section{References}

Adam S \& Batson S (1997) A study of problems associated with the delivery of enteral feed in critically-ill patients in five ICUs in the UK. Intensive Care Medicine 23, 261-266.

American Society for Parenteral and Enteral Nutrition Board of Directors (1995) Guidelines for the use of parenteral and enteral nutrition in adult and pediatric patients. Journal of Parenteral and Enteral Nutrition 17, Suppl., 1SA-52SA.

Bollmann MD, Berger MM, Revelly JP, Cayeux MC \& Chiolero (2001) Impact of energy balance on clinical outcome in ICU patients - preliminary results. Clinical Nutrition 20 Suppl. 3, 3.

Brandi LS, Bertolini R \& Calafà M (1997) Indirect calorimetry in critically-ill patients: clinical applications and practical advice. Nutrition 13, 349-358.

Bursztein S, Saphar P, Singer P \& Elwyn D (1989) A mathematical analysis of indirect calorimetry measurements in acutely ill patients. American Journal of Clinical Nutrition 50, 227-230.

Chioléro RL, Bracco D \& Revelly D (1993) Does indirect calorimetry reflect energy expenditure in the critically-ill patient. In Metabolic Support of the Critically-ill patient, pp. 95-118 [DW Wilmore and YA Carpentier, editors]. Berlin: Springer.

Coward WA (1988) The doubly-labelled water $\left({ }^{2} \mathrm{H}_{2}{ }^{18} \mathrm{O}\right)$ method. Proceedings of the Nutrition Society 47, 209-218.

Cuthbertson DP (1942) Post-shock metabolic response. Lancet i, 433-437.

Ebener C, Kramhöller H, Eder F, Röckelein W \& Jauch JW (2001) Enteral nutrition in critically ill surgical patients: do we meet caloric requirements in daily routine? Clinical Nutrition 20, Suppl. 3, 54.

Flakoll PJ, Hill JO \& Abumrad NN (1993) Acute hyperglycemia enhances proteolysis in normal man. American Journal of Physiology 265, E715-E721.

Franch-Arcas G, Plank LD, Monk DN, Gupta R, Maher K, Gillanders L \& Hill GL (1994) A new method for the estimation of the components of energy expenditure in patients with major trauma. American Journal of Physiology 267, E1002-E1009.

Frankenfield DC, Smith JS \& Cooney RN (1997) Accelerated nitrogen loss after traumatic injury is not attenuated by achievement of energy balance. Journal of Parenteral and Enteral Nutrition 21, 324-329.

Frankenfield DC, Wiles CE III, Bagley S \& Siegel JH (1994) Relationships between resting and total energy expenditure in injured and septic patients. Critical Care Medicine 22, 1796-1804.
Heyland DK (1998) Nutritional support in the critically-ill patients. A critical review of the evidence. Critical Care Clinics 14, 423-440.

Hill AG (2000) Initiators and propagators of the metabolic response to injury. World Journal of Surgery 24, 624-629.

Ishibashi N, Plank LD, Sando K \& Hill GL (1998) Optimal protein requirements during the first 2 weeks after the onset of critical illness. Critical Care Medicine 26, 1529-1535.

Jebb SA \& Prentice AM (1997) Assessment of human energy balance. Journal of Endocrinology 155, 183-185.

Jebb SA, Prentice AM, Goldberg GR, Murgatroyd PR \& Coward WA (1996) Changes in macronutrient balance during over- and under-feeding assessed by 12-d continuous wholebody calorimetry. American Journal of Clinical Nutrition 64, 259-266.

Jeejeebhoy KN (2001) Total parenteral nutrition: potion or poison? American Journal of Clinical Nutrition 74, 160-163.

Kirkland LL (1999) Factors impeding enteral tube feedings. Critical Care Medicine 27, 1383-1384.

Klein S, Peters EJ, Shangraw RE \& Wolfe RR (1991) Lipolytic response to metabolic stress in critically-ill patients. Critical Care Medicine 19, 776-779.

Klein CJ, Stanek GS \& Wiles CE (1998) Overfeeding macronutrients to critically ill adults: metabolic complications. Journal of the American Dietetic Association 98, 795-806.

Koea JB, Wolfe RR \& Shaw JHF (1995) Total energy expenditure during total parenteral nutrition: ambulatory patients at home versus patients with sepsis in surgical intensive care. Surgery 118, 54-62.

Livesey G \& Elia M (1988) Estimation of energy expenditure, net carbohydrate utilization, and net fat oxidation and synthesis by indirect calorimetry: evaluation of error with special reference to the detailed composition of foods. American Journal of Clinical Nutrition 47, 608-628.

Long CL, Kinney JM \& Geiger JW (1976) Nonsuppressibility of gluconeogenesis by glucose in septic patients. Metabolism 25, 193-200.

McClave SA, Sexton LK, Spain DA, Adams JL, Owens NA, Sullins MB, Blandford BS \& Snider HL (1999) Enteral tube feeding in the intensive care unit: factors impeding adequate delivery. Critical Care Medicine 27, 1252-1256.

McCowen KC, Friel C, Sternberg J, Chan S, Forse RA, Burke PA \& Bistrian BR (2000) Hypocaloric total parenteral nutrition: Effectiveness in prevention of hyperglycemia and infectious complications - A randomized clinical trial. Critical Care Medicine 28, 3606-3611.

McCowen KC, Malhotra A \& Bistrian BR (2001) Stress-induced hyperglycemia. Critical Care Clinics 17, 107-124.

Monk DN, Plank LD, Franch-Arcas G, Finn PJ, Streat SJ \& Hill GL (1996) Sequential changes in the metabolic response in critically injured patients during the first 25 days after blunt trauma. Annals of Surgery 223, 395-405.

Patino JF, de Pimiento SE, Vergara A, Savino P, Rodriguez M \& Escallon J (1999) Hypocaloric support in the critically ill. World Journal of Surgery 23, 553-559.

Plank LD, Connolly AB \& Hill GL (1998) Sequential changes in the metabolic response in severely septic patients during the first 23 days after the onset of peritonitis. Annals of Surgery $\mathbf{2 2 8}$, $146-158$.

Plank LD \& Hill GL (2000) Sequential metabolic changes following induction of systemic inflammatory response in patients with severe sepsis or major blunt trauma. World Journal of Surgery 24, 630-638.

Reid CL \& Campbell IT (2001) High energy deficits in MODS patients are associated with prolonged ICU length of stay but not mortality. Clinical Nutrition 20, Suppl. 3, 52. 
Shangraw RE, Jahoor F, Miyoshi H, Neff WA, Stuart CA, Herndon DN \& Wolfe RR (1989) Differentiation between septic and postburn insulin resistance. Metabolism 38, 983-989.

Shaw JHF, Wildbore M \& Wolfe RR (1987) Whole body protein kinetics in severely septic patients. Annals of Surgery 205, 288-294.

Smyrnios NA, Curley FJ \& Shaker KG (1997) Accuracy of 30-minute indirect calorimetry studies in predicting 24-hour energy expenditure in mechanically ventilated, critically-ill patients. Journal of Parenteral and Enteral Nutrition 21, $168-174$.

Speakman JR (1990) Principles, problems and a paradox with the measurement of energy expenditure of free-living subjects using doubly-labelled water. Statistics in Medicine 9, 1365-1380.

Streat SJ, Beddoe AH \& Hill GL (1987) Aggressive nutritional support does not prevent protein loss despite fat gain in septic intensive care patients. Journal of Trauma 27, 262-266.

Uehara M, Plank LD \& Hill GL (1999) Components of energy expenditure in patients with severe sepsis and major trauma: a basis for clinical care. Critical Care Medicine 2, 1295-1302.
Van den Berghe $G$, Wouters P, Weekers F, Verwaest C, Bruyninckx F, Schetz M, Vlasselaers D, Ferdinande P, Lauwers P \& Bouillon R (2001) Intensive insulin therapy in critically-ill patients. New England Journal of Medicine 345, 1353-1367.

Weissman C, Kemper M, Elwyn DH, Askanazi J, Hyman AI \& Kinney JM (1986) The energy expenditure of the mechanically ventilated critically-ill patient. An analysis. Chest 89, 254-259.

Wolfe RR (1996) Herman Award Lecture, 1996: Relation of metabolic studies to clinical nutrition - the example of burn injury. American Journal of Clinical Nutrition 64, 800-808.

Wolfe RR (1997) Substrate utilization/insulin resistance in sepsis/trauma. Baillière's Clinical Endocrinology and Metabolism 11, 645-657.

Wolfe RR \& Martini WZ (2000) Changes in intermediary metabolism in severe surgical illness. World Journal of Surgery 24, 639-647.

Zaloga GP \& Roberts P (1994) Permissive underfeeding. New Horizons 2, 257-263. 